\title{
Effects of Different Temperatures and Light Intensities on physiological characteristics of Didymodon vinealis
}

\author{
Ying Lv, Ling Tao, Jun Ren * \\ School of Environmental and Municipal Engineering, Lanzhou Jiao tong University, Lanzhou 730070, \\ Gansu, China \\ Corresponding author, E-mail: renjunjd@126.com
}

Keywords: Didymodon vinealis, temperature, light intensity, physiological characteristics.

\begin{abstract}
To obtain a better culture conditions and the optimum environmental factors for Didymodon vinealis (D. vinealis) in light incubator, effects of different light intensities (40, 120 and $\left.240 \mu \mathrm{E} . \mathrm{m}^{-2} . \mathrm{s}^{-1}\right)$ and temperatures $\left(15,20,25,30\right.$ and $\left.35{ }^{\circ} \mathrm{C}\right)$ on physiological characteristics of $D$. vinealis were studies under laboratory conditions. The results showed that Chla, MDA, soluble protein and soluble sugar contents of $D$. vinealis increased with the time and the light intensities increasing. MDA, soluble protein and soluble sugar contents got the minimum value at $30{ }^{\circ} \mathrm{C}$ and 40 $\mu \mathrm{E} \cdot \mathrm{m}^{-2} \cdot \mathrm{s}^{-1}$. In summary, it was found that the optimum environmental factors for the growth of $D$. vinealis were the temperature $30{ }^{\circ} \mathrm{C}$ and the light intensity $40 \mu \mathrm{E} \cdot \mathrm{m}^{-2} \cdot \mathrm{s}^{-1}$.
\end{abstract}

\section{Introduction}

Moss soil crusts (MSCs) can be used as indicators of environmental changes [1], Bryum argenteum and Didymodon vinealis are the main species of MSCs [2]. Growth of MSCs is a complex phenomenon requiring suitable environmental conditions to proceed properly, several environmental factors act synergistically on the growth and physiology of MSCs. Light and temperature are basic environmental factors affecting growth of all MSCs [3], photosynthesis, transpiration, carbohydrate metabolism, and other metabolic activities are all affected by temperature and light [4]. Temperature is one of the most important environmental factors affecting growth, reproduction, distribution, abundance and phenology, but also induces physiological responses in organisms [5], low temperatures decreases plant growth and vigor, temperatures above the normal optimum are perceived as heat stress by all living organisms [6]. Light is the main source of energy for carbon assimilation and growth, affecting plant adaptation and acclimation [7]. When these factors are insufficient, growth does not occur. In the present study, many research have discovered that physiological ecology and molecular mechanism of MSCs are affected by a series of environmental factors such as UV-B radiation[8] and drought stress [9], yet little is known of the effects of different light intensities and temperatures on physiological characteristics of Didymodon vinealis ( $D$. vinealis). Therefore, we chose $D$. vinealis as material, the purpose of this work was to obtain a better culture conditions and the optimum environmental factors for $D$. vinealis, and to investigate the physiological characteristics of $D$. vinealis by the changes of chlorophyll a (Chla), lipid peroxidation (MDA), soluble protein and soluble sugar contents.

\section{Materials and methods}

\subsection{Cultivation of $D$. vinealis}

D. vinealis, a common dominant species in MSCs, was isolated from Shapotou, Zhongwei County, Ningxia Hui Autonomous Region, China (N 37 2646.9", E 104 50’11.2") and identified by microscopy. $D$. vinealis were cultivated in MS medium at different light intensities (40, 120 and 240 $\left.\mu \mathrm{E} \cdot \mathrm{m}^{-2} \cdot \mathrm{s}^{-1}\right)$ and different temperatures $\left(15,20,25,30\right.$ and $\left.35^{\circ} \mathrm{C}\right)$ with a $12 \mathrm{~h} \mathrm{light} / 12 \mathrm{~h}$ dark cycle in light incubator (HPG-280B, China). 


\subsection{Chla measurements.}

To monitor the effects of different temperatures and light intensities on the growth of $D$. vinealis, the contents of Chla was assayed. Chla was extracted in 95\% ethanol and characterized by the method of Lan [10]. Absorbance values for the supernatants were recorded at $649 \mathrm{~nm}$ and $665 \mathrm{~nm}$ for Chla (UV-300, UK).

\subsection{Estimation of MDA}

MDA content was performed by the method of Xie [11] with some modifications, the absorbance of the supernatant was measured at 450, 532 and $600 \mathrm{~nm}$ (UV-300, UK).

\subsection{The determination of soluble protein}

Soluble protein assay was based on the method described by Bradford [12], absorbance was recorded at $595 \mathrm{~nm}$ (UV-300, UK), and protein concentrations were quantified using the Coomassie Brilliant Blue G-250 method using bovine serum albumin $\left(0-100 \mu \mathrm{g} \cdot \mathrm{mL}^{-1}\right)$ as the standard.

\subsection{Measurements of soluble sugar}

According to methods of Li[13] with minor modification, soluble sugars was determined, the absorbance at $630 \mathrm{~nm}$ was measured with a spectrophotometer (UV-300, UK), the standard curve for soluble sugar was prepared by sucrose (0-100 $\mu \mathrm{g} . \mathrm{mL}-1)$. Each experiment was performed at least in triplicate.

\subsection{Statistical analysis}

Data were analyzed by General Linear Model with the software Statistical Package for the Social Science (SPSS) version 19.0. Pairwise comparisons were performed using the least significant difference (LSD) procedure at the 0.05 significance level. Graphical work was carried out using Origin software 8.0.

\section{Results}

\subsection{Effect of different time, temperature and light intensity on Chla contents}

Effects of different time, temperatures and light intensities on Chla contents of $D$. vinealis was as Fig 1. The results showed that Chla contents were increased with time, temperature and light intensity increasing.
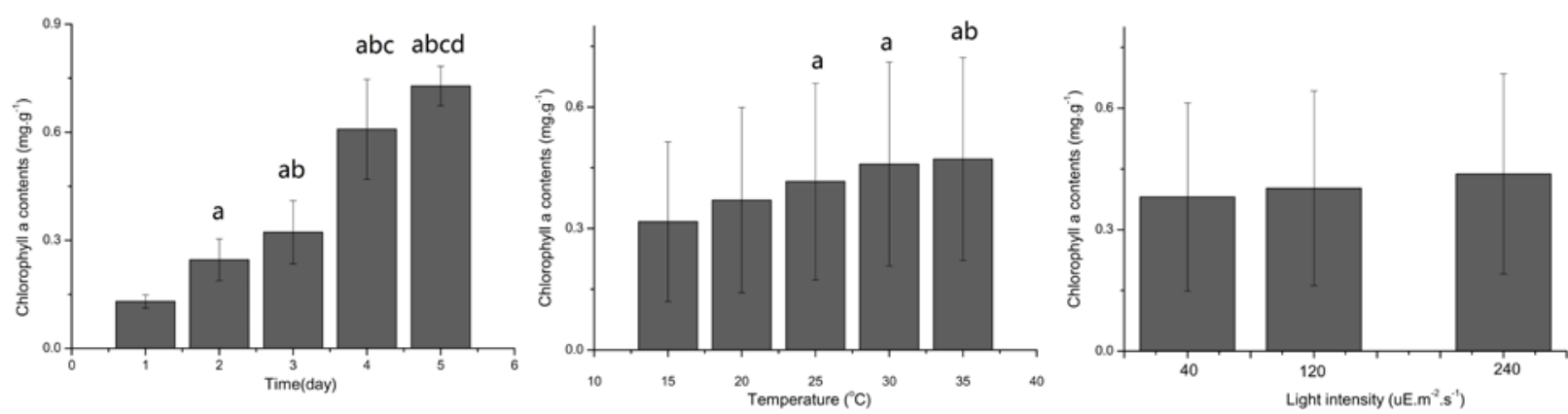

Fig. 1 Changes of chlorophyll a contents from Didymodon vinealis with different time, temperatures and light intensities. a, b, c, d respectively showed to consequently compare with different time, temperatures and light intensities, $\mathrm{p}<0.05$.

\subsection{Effect of different time, temperature and light intensity on MDA content}

In Fig 2, with time and light intensity increasing MDA contents increased, MDA content increased significantly with the temperature increasing $\left(>30^{\circ} \mathrm{C}\right)$ or decreasing $\left(<30^{\circ} \mathrm{C}\right)$, MDA content got the minimum value at $30^{\circ} \mathrm{C}$. The results showed that low or high temperature and high light intensity promoted the accumulation of MDA.

\subsection{Effect of different time, temperature and light intensity on soluble protein content}

In Fig 3, soluble protein contents increased with time and light intensities increasing, at 15 to $30{ }^{\circ} \mathrm{C}$, with temperature increasing soluble protein contents decreased, at 30 to $35{ }^{\circ} \mathrm{C}$, soluble protein 
contents increased again, soluble protein contents got the minimum value at $30^{\circ} \mathrm{C}$. The results showed that low or high temperature and high intensity stress induced the accumulation of soluble protein content.
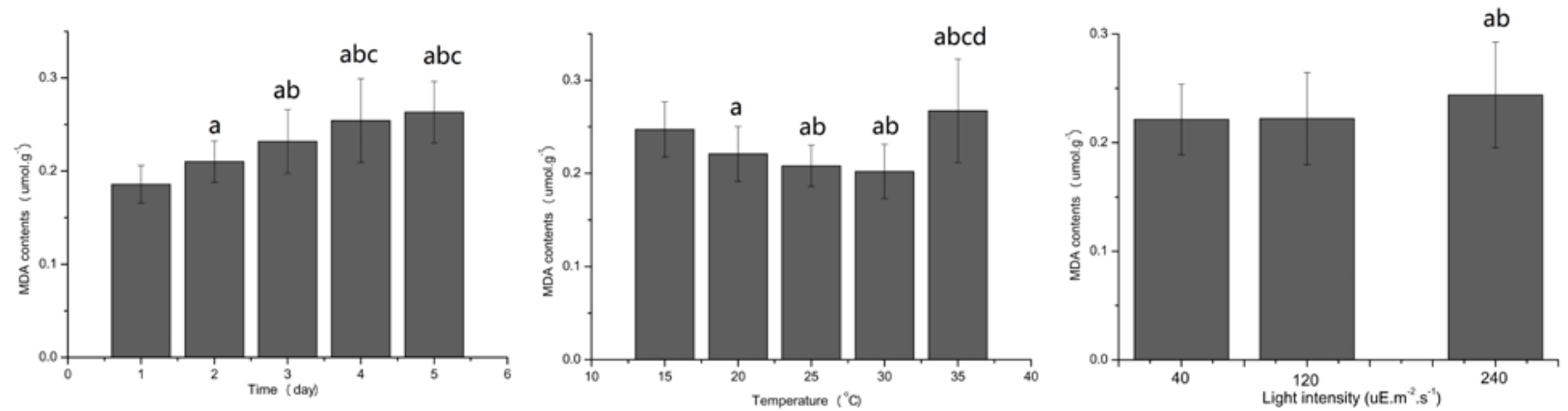

Fig.2 Changes of MDA contents from Didymodon vinealis with different time, temperatures and light intensities. a, b, c, d respectively showed to consequently compare with different time, temperatures and light intensities, $\quad \mathrm{p}<0.05$.
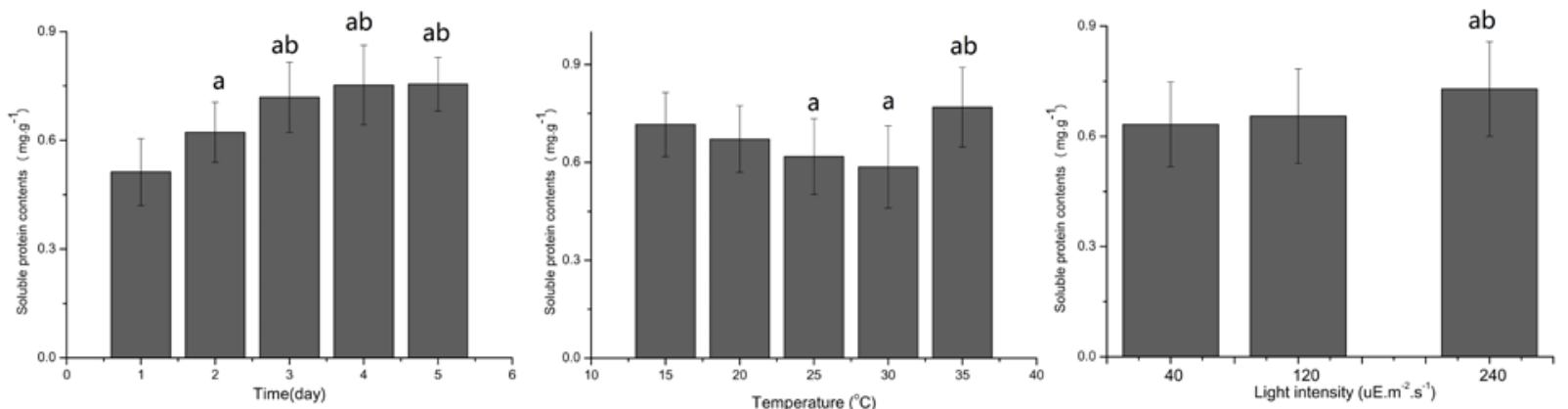

Fig.3 Changes of soluble protein contents from Didymodon vinealis with different time, temperatures and light intensities. a, b, c, d respectively showed to consequently compare with different time, temperatures and light intensities, $\mathrm{p}<0.05$.
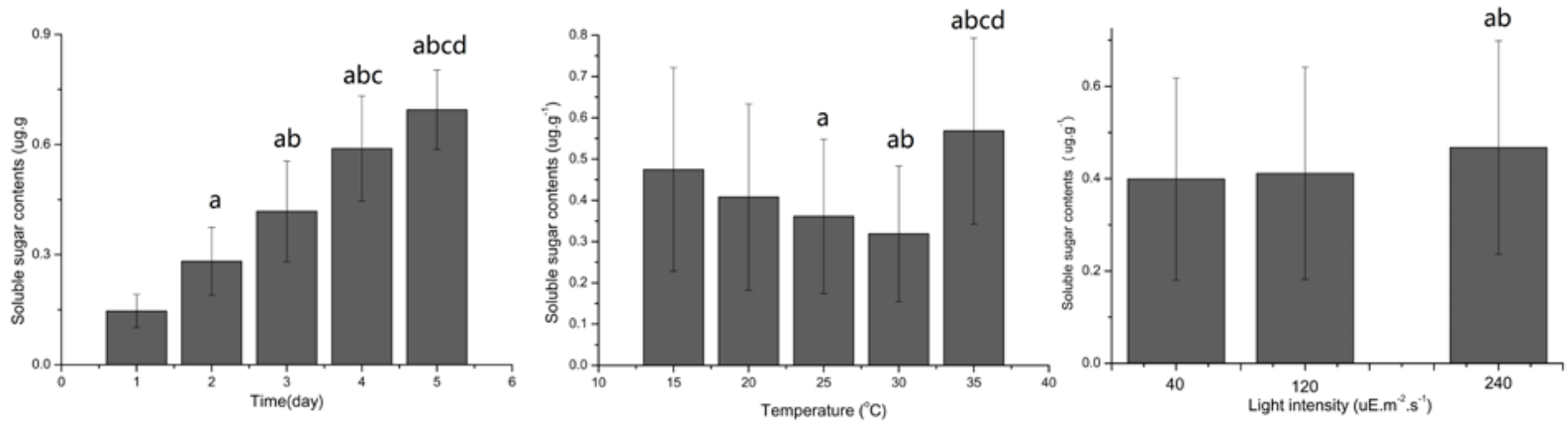

Fig.4 Changes of soluble sugar contents from Didymodon vinealis with different time, temperatures and light intensities. a, b, c, d respectively showed to consequently compare with different time, temperatures and light intensities, $\mathrm{p}<0.05$.

\subsection{Effect of different time, temperature and light intensity on soluble sugar}

In Fig 4, soluble sugar contents increased with time and light intensities increasing, at 15 to $30{ }^{\circ} \mathrm{C}$, with temperature increasing soluble protein contents decreased, at 30 to $35{ }^{\circ} \mathrm{C}$, soluble protein contents increased again, soluble sugar contents got the minimum value at $30^{\circ} \mathrm{C}$. The results showed that low or high temperature and high intensity stress induced the accumulation of soluble sugar content. 


\section{Discussion}

Plants resort many adaptive strategies in response to abiotic environmental stresses such as temperature and light intensity. These adaptive mechanisms include changes in physiological and biochemical processes [14].

Chla concentration is a useful quantitative indicator of the degree of MSCs development [15], Chla content also gives an indirect measure of nutrient status. In our study, Chla contents changed little at 30 to $35^{\circ} \mathrm{C}$, between 40 and $120 \mu \mathrm{E} \cdot \mathrm{m}^{-2} \cdot \mathrm{s}^{-1}$ Chla content changed little either, the results suggested that $D$. vinealis could adapt to the conditions and get well growth, it also showed that low temperature and high light intensity significantly inhibited the growth of $D$. vinealis, it could be seen that $D$. vinealis was very sensitive to low temperature and high light intensity stress in the process of growth.

MDA content is considered to be one of the most important manifestations of lipid peroxidation and its concentration is related to the degree of membrane lipid peroxidation [16]. Therefore, lipid peroxidation can be determined indirectly by measuring MDA concentration, the lower MDA content showed the smaller stress that the plants were suffered from, the higher MDA content indicated that the more serious oxidative damage was gotten by the plant cell membrane. In our study, MDA content increased significantly with the temperature increasing $\left(>30{ }^{\circ} \mathrm{C}\right)$ or decreasing $\left(<30^{\circ} \mathrm{C}\right)$, there was no difference between 40 and $120 \mu \mathrm{E} \cdot \mathrm{m}^{-2} . \mathrm{s}^{-1}$. The results showed that membrane damage had a close relationship to low or high temperature and high light intensity, temperature and light intensity stress made free radicals accumulate in cells, excess free radicals caused or aggravated membrane lipid peroxidation. MDA content got the minimum value at $30^{\circ} \mathrm{C}$. It showed that this temperature had little influence on $D$. vinealis and was suitable for the growth of $D$. vinealis.

The soluble proteins may constitute various antioxidant enzymes [17], the changes could reflect protein synthesis and degradation of various information in the cell. In our study, soluble protein content changed significantly with the temperature and the intensity changing. The results showed that soluble protein synthesis and accumulation were induced by the changed temperature and light intensity. The content of soluble protein content was the lowest at the same level at $30{ }^{\circ} \mathrm{C}$ and 40 $\mu \mathrm{E} \cdot \mathrm{m}^{-2} \cdot \mathrm{s}^{-1}$, it suggested that this temperature and light intensity were adapted to $D$. vinealis and made them grow well.

Soluble sugars may also function as a typical osmoprotectant, stabilizing cellular membranes, and maintaining turgor [18]. Plants will be induced to accumulate some soluble sugar in the external environment such as temperature and light intensity stress, and reduce the osmotic potential and freezing point to adapt to the change of external environment. In our study, soluble sugar content changed significantly with the light intensity and the temperature changing, the results showed that soluble sugar synthesis and accumulation were induced by the changing temperature and light intensity. Soluble sugar content was the lowest at the same level at $30{ }^{\circ} \mathrm{C}$ and $40 \mu \mathrm{E} . \mathrm{m}^{-2} . \mathrm{s}^{-1}$, it further indicated that this temperature and light intensity were adapted to $D$. vinealis and made them grow well.

\section{Summary}

In summary, it was found that the optimum environmental factors for the growth of $\mathrm{D}$. vinealis were the light intensity $40 \mu \mathrm{E} . \mathrm{m}-2 . \mathrm{s}-1$ and the temperature $30{ }^{\circ} \mathrm{C}$. Under the laboratory conditions $\mathrm{D}$. vinealis could grow rapidly and were gotten minimal stress in the external environment. The results could be provided theory and technical support for large-scale cultivation and field inoculation of D. vinealis. 


\section{References}

[1]Bargagli R. Environmental contamination in Antarctic ecosystems [J].Science of the Total Environment. vol. 400(2008) No. 1, p. 212-226.

[2] Barker D H, Stark L R, Zimpfer J F, et al .Evidence of drought - induced stress on biotic crust moss in the Mojave Desert[J].Plant, Cell \& Environment.vol.28(2005)No.7,p.939-947.

[3] Hroudová Z, Zákravský P.Germination responses of diploid Butomus umbellatus to light, temperature and flooding[J].Flora-Morphology, Distribution, Functional Ecology of Plants.vol.198 (2003) No.1,p.37-44.

[4] Monneveux P, Pastenes C, Reynolds M P.Limitations to photosynthesis under light and heat stress in three high-yielding wheat genotypes[J].J Plant Physiol.vol.160(2003)No.6,p.657-666.

[5] Jia F, Dou W, Hu F, et al .Effects of thermal stress on lipid peroxidation and antioxidant enzyme activities of oriental fruit fly, Bactrocera dorsalis (Diptera: Tephritidae)[J].Florida Entomologist. vol.94 (2011) No. 4, p. 956-963.

[6] Nguyen T M, Bressac C, Chevrier C.Heat stress affects male reproduction in a parasitoid wasp[J].J Insect Physiol.vol.59(2013)No.3,p.248-254.

[7] Valladares F, Niinemets Ü.Shade tolerance, a key plant feature of complex nature and consequences [J].Annual Review of Ecology, Evolution, and Systematics. vol. (2008) No. 237-257.

[8] Hui R, Li X, Zhao R, et al .UV-B radiation suppresses chlorophyll fluorescence, photosynthetic pigment and antioxidant systems of two key species in soil crusts from the Tengger Desert, China[J].Journal of Arid Environments.vol.113(2015)No.6-15.

[9] Xu S J, Liu C J, Jiang P A, et al .The effects of drying following heat shock exposure of the desert moss Syntrichia caninervis[J].Sci Total Environ.vol.407(2009)No.7,p.2411-2419.

[10] Lan S, Wu L, Zhang D, et al .Ethanol outperforms multiple solvents in the extraction of chlorophyll-a from biological soil crusts [J].Soil Biology and Biochemistry. vol.43 (2011) No.4,p. 857-861.

[11] Xie Z, Wang Y, Liu Y, et al .Ultraviolet-B exposure induces photo-oxidative damage and subsequent repair strategies in a desert cyanobacterium Microcoleus vaginatus Gom.[J].European Journal of Soil Biology.vol.45(2009)No.4,p.377-382.

[12] Bradford M M.A rapid and sensitive method for the quantitation of microgram quantities of protein utilizing the principle of protein-dye binding [J].Analytical biochemistry. vol.72 (1976) No.1,p. 248-254.

[13] Li M, Feng S, Wu L, et al .Sugar-rich sweet sorghum is distinctively affected by wall polymer features for biomass digestibility and ethanol fermentation in bagasse[J].Bioresour Technol. vol.167 (2014) No.14-23.

[14] Shu X, Zhang Q, Wang W.Effects of temperature and light intensity on growth and physiology in purple root water hyacinth and common water hyacinth (Eichhornia crassipes)[J].Environ Sci Pollut Res Int.vol.21(2014)No.22,p.12979-12988.

[15] Castle S C, Morrison C D, Barger N N.Extraction of chlorophyll a from biological soil crusts: A comparison of solvents for spectrophotometric determination[J].Soil Biology and Biochemistry. vol.43 (2011) No.4, p. 853-856.

[16] Meng J, Zhang C, Zhu F, et al .Ultraviolet light-induced oxidative stress: effects on antioxidant response of Helicoverpa armigera adults [J].Journal of insect physiology.vol. 55(2009) No.6, p.588-592. 
[17] Srivastava S, Mishra S, Dwivedi S, et al .Nickel phytoremediation potential of broad bean, Vicia faba L., and its biochemical responses[J].Bulletin of environmental contamination and toxicology. vol.74 (2005) No.4, p. 715-724.

[18] Gibson S I.Control of plant development and gene expression by sugar signaling [J].Curr Opin Plant Biol.vol.8 (2005) No.1, p. 93-102. 